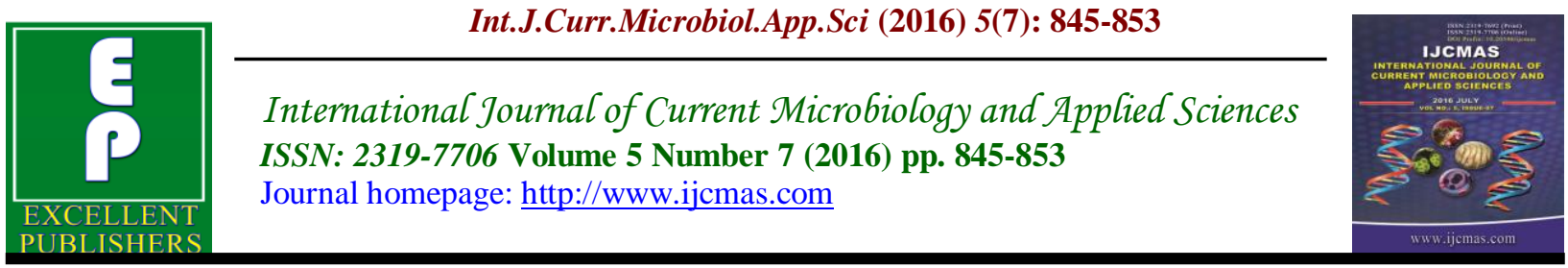

Original Research Article

http://dx.doi.org/10.20546/ijcmas.2016.507.097

\title{
Use of Mustard Oil Cake for Protease Production by Bacillus subtilis
}

\author{
Pallavi S. Badhe ${ }^{1}$, Manasi A. Damale ${ }^{2}$ and Ravindra Adivarekar ${ }^{1} *$ \\ Department of Fibres and Textile Processing Technology, Institute of Chemical Technology, \\ N.P. Marg, Matunga, Mumbai, 400019, India \\ *Corresponding author
}

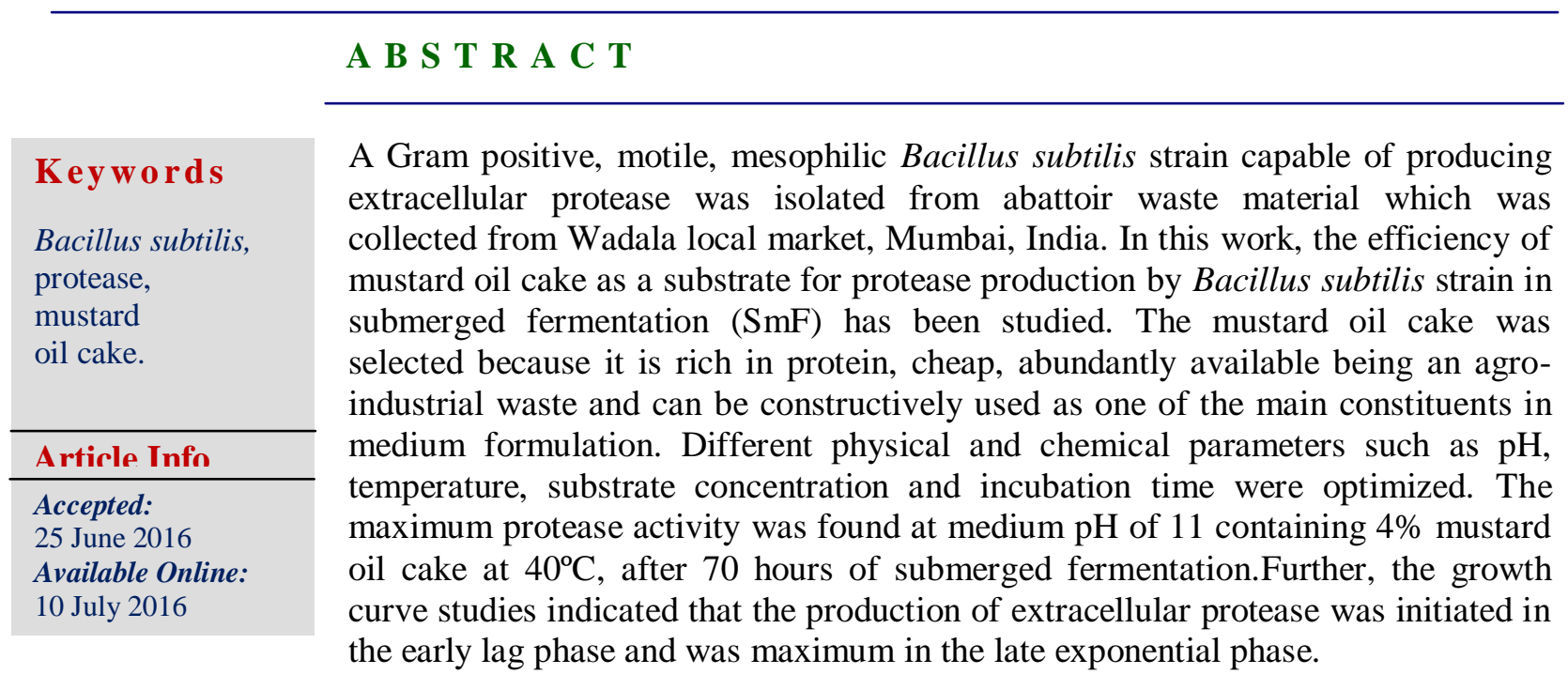

\section{Introduction}

These enzymes mainly function in a narrow range of $\mathrm{pH}$, temperature, and ionic strength. Moreover, the technological application of enzymes under demanding industrial conditions makes the currently known enzymes ineffective. The microorganisms from diverse and exotic environments called as extremophiles, are an important source of enzymes, whose specific properties are expected to result in novel process applications (Kumar and Takagi, 1999).

Enzymes have significant advantages over chemical catalysts of which the most important is specificity, high catalytic activity, ability to work at moderate as well as extreme temperatures and the ability to be produced in large qualities. Proteases (proteinases, peptidases or proteolytic enzymes) are enzymes that break peptide bonds between amino acids of proteins. Proteases represent one of the three largest groups of industrial enzymes and account for about $60 \%$ of the total worldwide sale of the enzymes. The proteases execute a large variety of functions extending from cellular level to organ and organism level, to produce cascade systems such as homeostasis and inflammation (Rao et al., 1998).

Microbial proteases have tremendous potential to offer to the mankind. Proteases 
are widely used in several industrial sectors such as detergent, food, pharmaceutical, chemical, leather, silk, cleaning contact lenses/denatures, dewooling of animal skin, recovery of soluble proteins and amino acids from chrome leather wastes and waste treatment etc (Malathi and Chakraborty, 1991; Rajkumar et al., 2011). Proteases play a critical role in many physiological processes including protein catabolism, blood coagulation, cell growth and migration, tissue arrangement, morphogenesis in development, inflammation, tumor growth and metastasis, activation of zymogens (Delepelaire and Wandersman, 1989), release of hormones and pharmacologically active peptides from precursor proteins and transport of secretory proteins across membranes (Rawlings and Barett, 1993).

Microbial proteases are among the most important hydrolytic enzymes and have been studied extensively since the advent of enzymology. They are essential constituents of all forms of life on earth, including prokaryotes, fungi, plants and animals. They can be cultured in large quantities in relatively short time by established fermentation methods and produce an abundant, regular supply of the desired product.

Enzymes find its application in almost all branches. Today most applications for industrial enzymes are found in food industry i.e. protease for tenderization of meat and improvement to the solubility, emulsification, gelling if foaming properties of various other foods. In the wine industry the use of pectinase preparation is permitted to increase juice yield.

The detergent industry is currently largest user of industrial enzymes and employs protease, lipase, amalyase and cellulases predominantly in the production of biological washing powder. These enzymes quickly breakdown and release the dirt that normally can be removed at much higher temperatures or by using large quantities of chemical detergents over a longer time period.

The use of enzymes in textile industry is one of the most rapidly growing field in industrial enzymology (Mojsov, 2011). The textile industry has been condemned as being one of the world's worst offenders in terms of pollution because it requires a great amount of chemicals. As many as 2,000 different chemicals are used in the textile industry to aid transfer of colourants and finishing agents using water which is a finite resource and quickly becoming scarce. In every step in textile processing water is not only used to transfer the actives on the textiles but also to wash them out before beginning the next step. The water becomes full of chemical additives and is then expelled as wastewater; which in turn pollutes the environment. Now-a-days enzymes are becoming an integral part of the textile processing due to increased awareness about the environmental concerns and related regulations as the enzymes are biodegradable and work under mild condition, saving the precious energy.

Protease is one such enzyme which can be applied in textile industry to remove stiff and the dull gum layer of sericin from the raw silk to achieve improve luster and softness. Protease treatment can modify the surface of wool and silk fibers to provide new and unique finishes (Doshi and Shelke, 2001).

From environmental as well as economical point of view, there is growing research interest to explore use of waste sources as nutrient for medium formulation in 
production of various enzymes. Conversion of wastes into useful biomass by microorganism and their enzymes is a new trend. Crop residues such as bran, husk, bagasse and fruit seeds are utilized as a potential raw material in bioprocesses as they provide an excellent substrate for the growth of microorganism supplying the essential nutrients to them (Ramachandran et al., 2007).

Oil cakes are by-products obtained after oil extraction from the seeds. Many scientists have worked i.e. ( Rekha et al., 2012) describing production of lipase enzymes using ground nut oil cake and linseed oil cakes as substrate in solid state fermentation (SSF). Oil cakes are ideally suited nutrient support in SSF rendering both carbon and nitrogen sources, and are reported to be good substrate for enzyme production.

In extracellular protease production, use of solid substrate such as soya bean meal (Miller et al., 1967), rice bran, wheat bran, ground nut oil cake, gingili oil cake, coconut oil cake (Bhaskar et al., 2008) and green gram husk ( Kumar et al., 2008) has been reported as culture medium ingredient.

Among the various agro wastes, Mustard oil cake (MOC) contains two major components; protein $38.5 \%$ and fiber $3.5 \%$. Amino acid profile of MOC shows them to be rich in leucine, phenylalanine, arginine and glycine (Johnvesly et al., 2002). This solid substrate not only supplies the nutrient to the culture but also serves as an anchorage for the microbial cells, where cost and availability are important considerations (Gattinger et al., 1990).

The majority of the waste in the meat industry is produced during slaughtering. Slaughter house waste consist of the portion of a slaughtered animal that cannot be sold as meat or used in meat- products. These waste are most of the time dumped to degrade. We have used such degraded waste for our study, as it is available freely and in large amount. Moreover, it is inexpensive source, as it is a waste one (Badhe et al., 2016).

Under this study the optimization for the maximum protease production by $B$. subtilis in solid state flask (SSF) cultures is attempted. The optimization of the SSF system was based on the medium composition and establishment of cultural conditions using mustard oil cake as substrate. Augmenting the productivity of protease in solid state culture may be of great benefit as the lower production cost of protease could lead to new industrial applications.

\section{Materials and Methods}

Mustard oil cakes were obtained from a Narayana town in Rajasthan, India and were ground using a mill and then autoclaved at $121^{\circ} \mathrm{C}$ for 15 minutes. The chemicals viz. gelatine yeast extract, agar and casein were of bacteriological grade and supplied by HiMedia, Mumbai, India. All the other chemicals were procured from S.D. Fine chemicals Ltd., Mumbai, India.

\section{Sample for bacterial isolation}

Abattoir waste was collected from local market, Wadala, Mumbai, India in sterile container and was stored at $4^{\circ} \mathrm{C}$ until use.

\section{Bacteria isolation and screening}

For enrichment of protease producing bacteria, collected samples were inoculated in Gelatine Yeast extract (GYE) broth. The broth contained $1 \%$ gelatine, $1 \%$ glucose, $0.2 \%$ yeast extract and $100 \mathrm{~mL}$ distilled 
water. The $\mathrm{pH}$ was adjusted to 7.0 and the broth was autoclaved at $121^{\circ} \mathrm{C}$, for 15 minutes. Then, $1 \mathrm{~mL}$ of degraded abattoir waste sample was inoculated in aseptic conditions in the above broth and incubated for $24 \mathrm{~h}$ at $40^{\circ} \mathrm{C}$.

A volume of $0.5 \mathrm{~mL}$ from the enrichment broth was serially diluted to $10^{-8}$ dilution and was spread plated on nutrient agar media prepared using $100 \mathrm{~mL}$ distilled water. Colonies obtained were further subjected to secondary screening by using Gelatine Yeast Extract (GYE) agar, pH 7.0 and incubated at $40^{\circ} \mathrm{C}$, for $24 \mathrm{~h}$.

Slant agar medium in Petri plate was overlaid with $0.25 \%$ tannic acid solution for 20 min. Tannic acid solution was then drained off and the slant agar medium was washed with several exchanges of distilled water in order to remove any superficially adhered tannic acid. Diameter (D) of the clear hydrolytic zone around the colonies and the diameter (d) of the colonies were measured. The ratio D:d was calculated and on basis of this value, the proteolytic strains were selected.

The isolate with enzymatic activity were primarily identified by Gram staining and morphological studies. The taxonomic identification was carried out at National Centre for cell science (NCCS), University of Pune Campus, using 16S rRNA method.

\section{Protease production and fermentation condition optimization}

Protease production using selected strain Bacillus subtilis was carried out by submerged fermentation. A liquid medium containing $1.0 \%$ yeast extract, $1.0 \%$ glucose and $1.0 \%$ mustard oil cake powder with $\mathrm{pH}$ adjusted to 7.0 was sterilized by autoclaving at $121^{\circ} \mathrm{C}, 15$ psi for $15 \mathrm{~min} .1 \%$ inoculums of $24 \mathrm{~h}$ old Bacillus subtilis culture $\left(10^{8}\right.$ $\mathrm{CFU} / \mathrm{ml}$ ) was then added to $50 \mathrm{~mL}$ of the medium (in conical flask of $100 \mathrm{~mL}$ volume). The flasks were incubated at $40^{\circ} \mathrm{C}$ for different time intervals on a rotary shaker at $150 \mathrm{rpm}$. The absorbance of the culture was measured by spectrophotometer at wavelength of $660 \mathrm{~nm}$. The culture was then centrifuged at $5000 \mathrm{rpm}, 20 \mathrm{~min}$ and the cell free supernatant was assayed for protease activity. In order to achieve maximum protease activity, medium parameters such as, incubation period, $\mathrm{pH}$ of the medium, incubation temperature, mustard oil cake powder concentration, and yeast extract concentration were optimized. Medium optimization studies were carried out by studying one parameter at a time keeping other parameters constant. Biomass production and protease biosynthesis was determined at interval of $1 \mathrm{~h}$. All experiments were done in triplicates.

\section{Protease activity assay}

Caseinolytic activity was assayed by the colorimetric method. A volume of $2000 \mu \mathrm{l}$ of cell free supernatant was incubated with $1000 \mu \mathrm{l}$ of substrate (casein, $0.65 \%$, w/v, $\mathrm{pH}$ 8.0) at temperature of $37^{\circ} \mathrm{C}$ for 30 minutes under static conditions. After adding $0.5 \mathrm{~mL}$ of Folin- ciocalteu reagent, the mixture was kept for $5 \mathrm{~min}$ at room temperature. Mixture was finally diluted to $10 \mathrm{~mL}$ with deionised water $(8 \mathrm{~mL})$. The absorbance of the reaction mixture was measured at $660 \mathrm{~nm}$. One unit of enzyme was defined as the amount of enzyme which catalyses the formation of $1 \mu \mathrm{mol}$ of tyrosine during one minute (Lowery et al., 1951).

\section{Statistical analysis}

All determinations were obtained from triplicate measurements and results were expressed as mean \pm standard deviation. 
Student's T test was used to analyze data and statistical significance was declared at $p$ $<0.05$.

\section{Results and Discussion}

6 bacteria strains were obtained by primary screening. Out of these 3 bacteria strains were found to be protease producers which were detected after flooding GYE agar plates with $0.25 \%$ tannic acid solution in secondary screening. These 3 bacterial strains received identification codes PSB1, PSB2 and PSB3. The proteolytic strain showing maximum $\mathrm{D} / \mathrm{d}$ value is 1.6 i.e. strain PSB2 was selected for further experiments as compare to PSB1 and PSB 3.

Gram staining and morphological examination of the isolate PSB2 revealed that it is Gram positive bacteria; rod shape sporulating microorganism with terminal endospore showing white colonies by growth on GYE agar.

\section{Effect of incubation time}

Production of extracellular protease was evaluated up to $75 \mathrm{~h}$ of submerged cultivation. (Figure 1). It was observed that extracellular protease production is directly proportional with growth of Bacillus subtilis. Maximum activity was $402.91 \mathrm{U} / \mathrm{ml}$ and it was found after $70 \mathrm{~h}$ of incubation in late exponential phase of the growth of the culture. After that activity decreased as growth of the Bacillus subtilis showed decreasing pattern. Similar results were reported in Bacillus odyssey with $72 \mathrm{~h}$ incubation period (Sandya and Tembeker, 2013).

\section{Effect of pH}

Change in $\mathrm{pH}$ of the system changes ionization state of the components of the system, due to which accessibility of substrate into bacterial cell changes. Hence enzyme production also varies as $\mathrm{pH}$ of the nutrient medium is altered. It was observed from figure 2 that, maximum protease production by $B$. subtilis occurs at $\mathrm{pH} 11.0$. Similar results of protease production were also reported by (Shikha et al., 2006 )at pH 11.0.

Fig.1 Effect of incubation time on extracellular Bacillus subtilis protease production

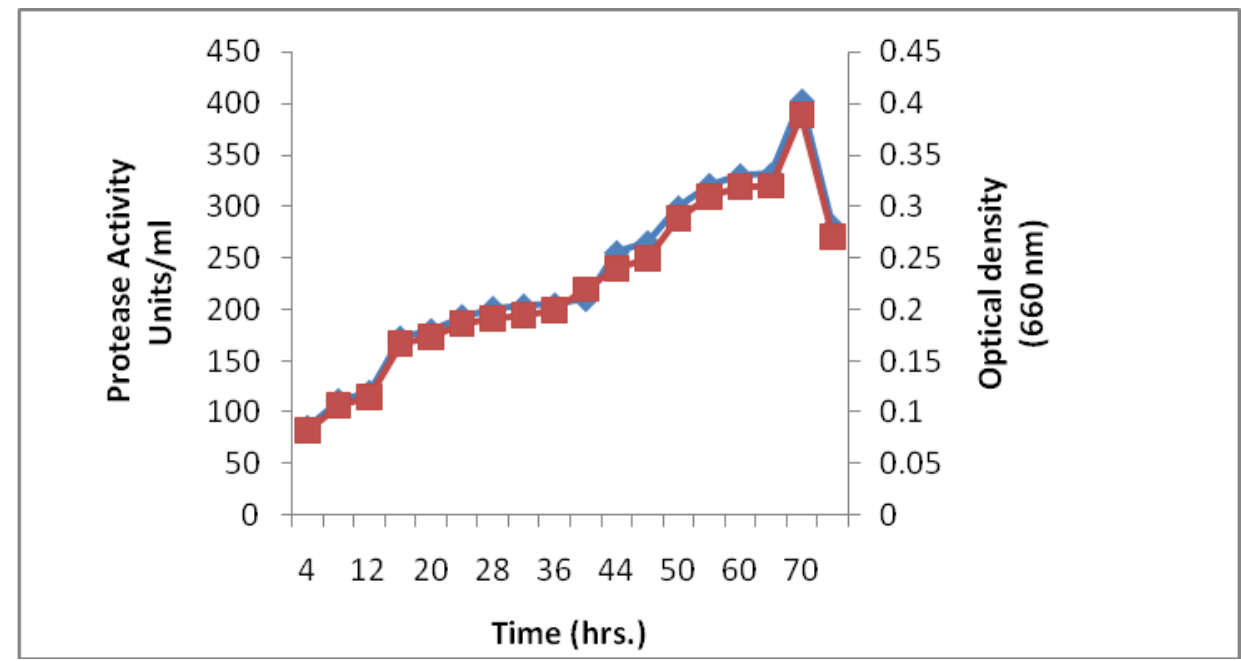

Effect of incubation time on extracellular Bacillus subtilis protease production.

Diamonds represent protease activity in units $/ \mathrm{mL} / \mathrm{min}$ and squares indicate optical density at $660 \mathrm{~nm}$. 
Fig.2 Effect of pH on extracellular Bacillus subtilis protease production

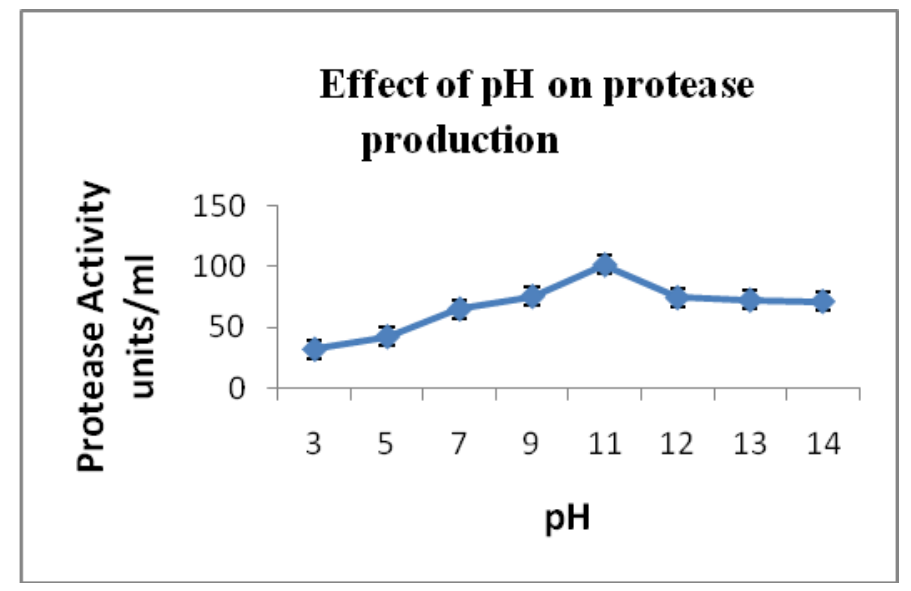

Fig.3 Effect of temperature on extracellular Bacillus subtilis protease production

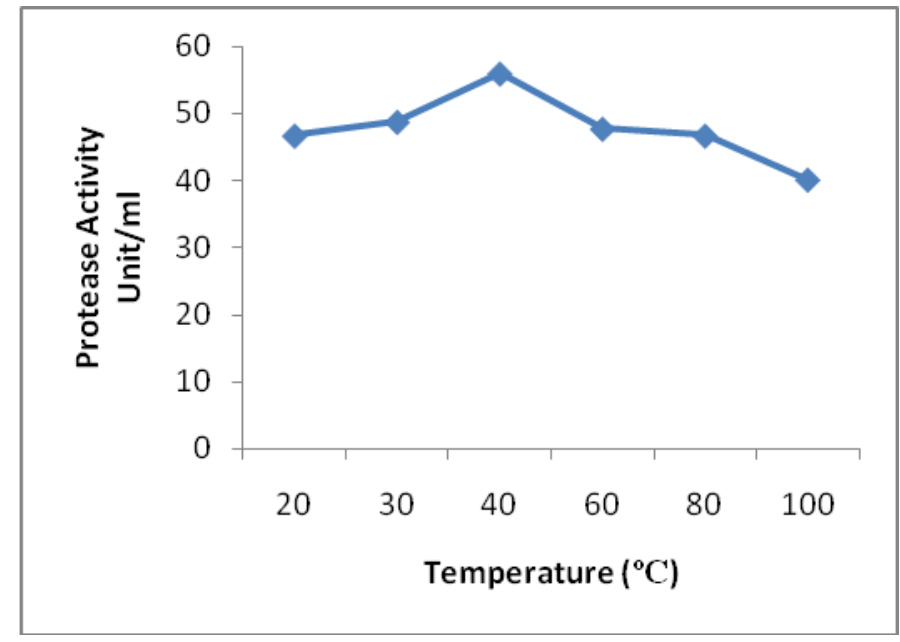

Fig.4 Effect of substrate concentration on extracellular Bacillus subtilis protease production

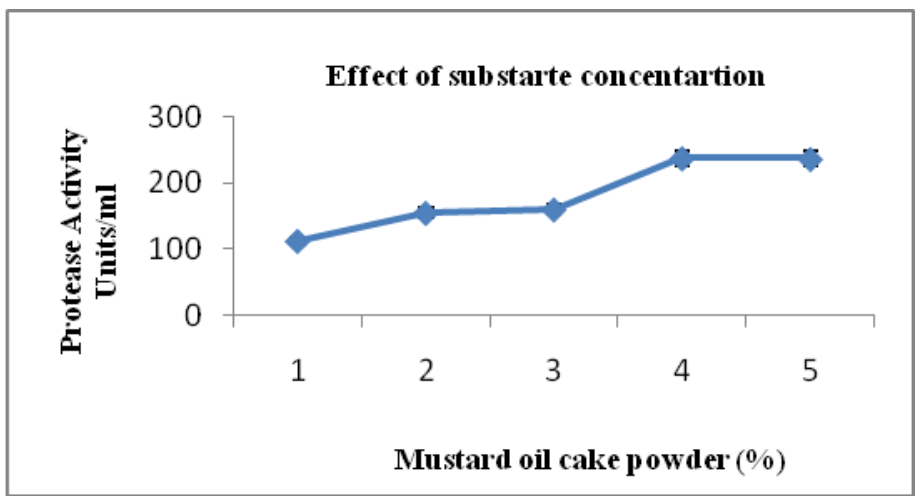


Fig.5 Effect of yeast extract concentration on extracellular Bacillus subtilis protease production

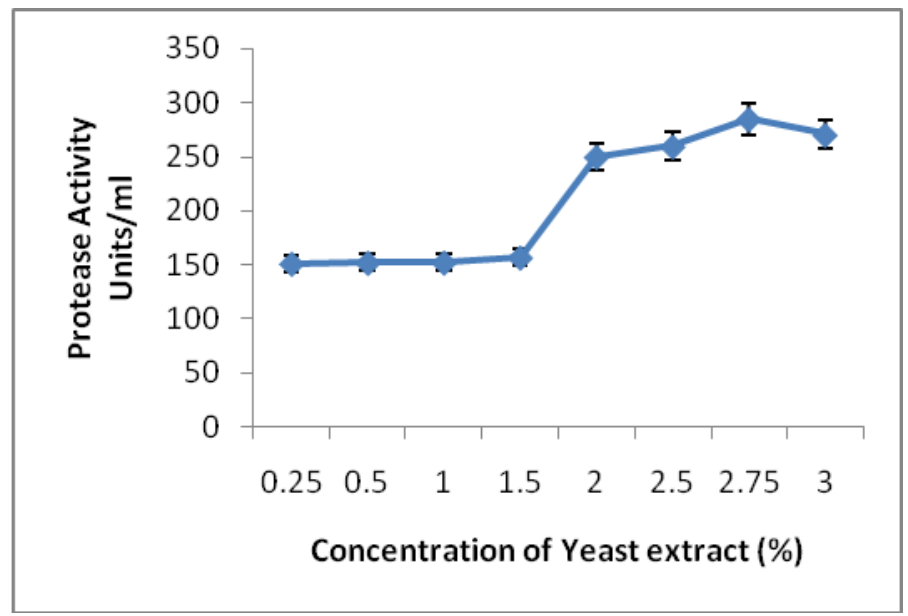

\section{Effect of temperature}

Temperature is one of the major factors that affect enzyme production by the isolate. Optimum temperature for protease production coincides with optimum growth temperature for the isolate. It has been observed that, generally protease is produced in the temperature range $20-50^{\circ} \mathrm{C}$. In this study, optimum temperature for maximum protease production was found to be $40^{\circ} \mathrm{C}$ as can been observed from Figure 3. Bacillus sp. showing protease production at $40^{\circ} \mathrm{C}$ has been already reported by (Sharma, 2012).

\section{Effect of substrate concentration}

Oil cakes have been widely used as substrates for the production of industrial enzymes using fermentation process since they provide both carbon and nitrogen sources in the nutrient medium (Ramchandran et al., 2007).

Figure 4 reveals that increase in the concentration of mustard oil cake powder showed increased production of extracellular protease. However, beyond $4 \%$ mustard oil cake powder in production medium, the production of the protease was observed to decrease. This may be due to increase in the viscosity of the medium beyond $4 \%$ of mustard oil cake powder which did not support appreciable growth of B. subtilis. Due to this, $4 \%$ of mustard oil cake in the medium was considered to be optimum for maximum protease production.

\section{Effect of yeast extract concentration}

Figure 5 indicates that the supplementation of the fermentative medium with yeast extract present a positive effect on the protease activity. A concentration of $2.75 \%$ yeast extract was found to be optimum for the extracellular protease production. Further increase in yeast extract concentration showed inhibition of enzyme activity. The result revealed that the best nitrogen source was yeast extract for Bacillus subtilis which showed highest level of protease activity. N.S.Nisha and J. Divakaran studied the effect of various nitrogen sources on protease production, and they found that yeast extract gives maximum protease activity (Nisha and Divakaran, 2014).

The Bacillus subtilis strain isolated from slaughter house waste material was found capable to produce extracellular protease 
enzyme. For maximal yield of enzyme production the fermentation parameters were optimized. Use of mustard oil cake as ingredients in fermentative medium for submerged cultivation of bacterium and extracellular protease production makes process economically viable. Based on the present study, it is concluded that Bacillus subtilis has wide scope for the industrial production of protease under solid state flask fermentation using mustard oil cake.

\section{Acknowledgements}

The authors would like to acknowledge Dr. Yogesh Shouche, Mr. Amit Yadav and Mr. Hitendra Munot of National centre for cell science (NCCS), Pune for their valuable contribution in identification of the isolate. Authors are also thankful to DST and TEQIP for providing the required instrument facility.

\section{References}

Badhe, P., Joshi, M., Adivarekar, R. 2016. Optimized production of extracellular proteases by Bacillus subtilis from degraded abattoir waste, J. BioSci. Biotechnol., 5(1): 29-36.

Bhaskar, V., Jones, Raj, T.R., Kandasamy, S.K.J., Vijaykumar, P., Anant, Achary. 2008. Optimization of production of subtilisin in solid substrate fermentation using response surface methodology, African J. Biotechnol., 7: 2286- 2291.

Delepelaire, P., Wandersman, C. 1989. Protease secretion by E. chrysanthemi, J. Biol. Chem., 264: 9083-89.

Doshi, R., Shelke, V. 2001. Enzymes in Textile Industry - An environmentalfriendly approach, Indian J. Fiber and Textile Res., 26: 202-205.

Gattinger, L.D., Duvniak, A., Khan, A.W. 1990. The use of canola meal as a substrate for xylase production by
Trichoderma reesei, Appl. Microbiol. Biotechnol., 33: 21-25.

Johnvesly, B., Manjunath, B.R., Naik, G. R. 2002. Pigeon pea waste as a novel, inexpensive substrate for production of thermostable alkaline protease from thermoalklophilic Bacillus sp. JB-99, Biores. Technol., 82: 61-64.

Kumar, C.G., Takagi, H. 1999. Microbial alkaline proteases: a from bioindustrial viewpoint, Biotechnol. Adv., 17: 561594.

Kumar, Praveen, P.K., Mathivanan, V., Karunakaran, M., Renganathan, S., Sreenivasan, R.S. 2008. Studies on the effects of $\mathrm{pH}$ and incubation period on protease production by Bacillus spp. Using groundnut cake and wheat bran, Indian J. Sci. Technol., 1: 1-4.

Kiro, Mojsov. 2011. Application Of Enzymes In The Textile Industry: A Review , International Congress "Engineering, Ecol. Materials in the Processing Industry” Jahorina, March 09th to 11th.

Lowry, O.H., Rosebrough, N.J., Farr, A.L., Randall, R.J. 1951. Protein measurement with Folin phenol reagent. J. Biol. Chem., 193: 265- 275.

Malathi, S., Chakraborty, R. 1991. Production of alkaline protease by a New Aspergillus flavus isolate under solid state fermentation for use as a depilation agent, Appl. Environ. Microbiol., 57: 712- 716.

Miller, R.W., VanEtten, C.H., McGraw, Clara., Wolff, I.A., Jones, Q. 1962. Amino acid composition of seed meals from forty-one species of cruciferae, J. Agri. Food Chem., 10: 426-430.

Nisha, N.S., Divakaran, J. 2014. Optimization Parameters for Alkaline protease Production using Bacterial isolates from different coastal regions of Tamil Nadu, India, Int. J. Curr. Microbiol. Appl. Sci., 3(8): 500-505. 
Rajkumar, Renganathan, Kothilmozhian, Ranishree, J., Ramasamy, R. 2011. Production and Characterization of a Novel Protease from Bacillus sp. RRM1 under Solid State Fermentation, J. Microbiol. Biotechnol., 21: 627-636.

Rao, M.B., Tanksale, A.M., Ghatge, M.S., Deshpande, V.V. 1998. Molecular and biotechnological aspects of microbial protease, Microbiol. Mol. Biol. Rev., 62: 597-635.

Ramchandra, S., Singh, S., Larroche, C., Soccol, C., Pandey, A. 2007. Oil cakes and their Biotechnological applications - A review, Biores. Technol., 98: 2000-2009.

Rawlings, N.D., Barett, A.J. 1993. Evolutionary families of peptidases, Biochem. J., 290: 205-218.

Rekha, K.S., S., Dr. Chandana Lakshmi, M. V.V., Dr. Sri Devi. V., Kumar siddartha, M. 2012. Production And Optimization Of Lipase From Candida Rugosa Using Groundnut Oilcake Under Solid State Fermentation, Int. J. Res. Engineering and Technol., 1: 4. Sandhya, D., Tambekar., Tambekar, D.H. 2013. Optimization of the production and partial characterization of an extracellular alkaline protease from thermo-halo-alkalophillic lonar lake bacteria, Biosci. Discovery, 4(1): 3038.

Sharma, N. 2012. Alkaline protease production by solid state fermentation of mustard oil cake, J. Pharmacy, 2: 35-40.

Shikha, A.S., Nandan, S.D. 2006. Improved production of alkaline protease from a mutant of alkalophilic Bacillus pantotheneticus using molasses as a substrate, Biores. Technol., 98: 881885 .

\section{How to cite this article:}

Pallavi S. Badhe, Manasi A. Damale and Ravindra Adivarekar. 2016. Use of Mustard Oil Cake for Protease Production by Bacillus subtilis. Int.J.Curr.Microbiol.App.Sci. 5(7): 845-853. doi: http://dx.doi.org/10.20546/ijcmas.2016.507.097. 